\title{
Narzędzia powrotu. Ludowe, wiejskie i chłopskie w poezji Piotra Szewca
}

\section{Tools of Return: the Folk, the Rural and the Peasant in the Poetry of Piotr Szewc}

Abstract: The following considerations are accompanied by the assumption that the poetry of Szewc should be primarily viewed in the framework of opinions represented by the researchers of the older generation and not in the context of the recent discussions about the place of Polish village in the culture. Influential - to the extent most interesting to the author: the reflection concerning the village - were poet's memories from the time of his childhood and early adulthood, which coincided with the 60s and the 70s. Most probably the majority of poetic village visions in his poetry was formed as a result of the earliest experiences. The analysed poems come from different periods in poet's life, some of them are still awaiting their publication. In the article the knowledge regarding village sociology, philosophy of things and the Jewish Kabbalah was utilised. The object of the utmost intensive consideration were the handy peasant tools. The author poses a question as to their presence in the poems, their role and the reason why Szewc remembers them in this particular way. The author also reminiscences over the way the elementary ideas of village, peasantry, folk culture or folklore are being defined, which leads to the remarks of a more general character on what is the folk culture in today's poetry and in what way its modern version coexists with the tradition.

Keywords: peasant tools, Jewish Kabbalah, folk culture, folklore, village, Piotr Szewc

Streszczenie: Rozważaniom towarzyszy założenie, że poezję Szewca należy przede wszystkim widzieć w układzie poglądów badaczy starszej generacji, a nie w kontekście najnowszych dyskusji o miejscu polskiej wsi w kulturze. Wpływ na to miały - w zakresie, który będzie mnie tu przede wszystkim interesował, refleksji na temat wsi - wspomnienia poety z okresu dzieciństwa i wczesnej młodości, przypadającego na lata sześćdziesiąte i siedemdziesiąte. Prawdopodobnie większość poetyckich obrazów wsi w tej poezji została ukształtowana w wyniku najwcześniejszych doświadczeń. Analizowane wiersze pochodzą z różnych okresów życia poety, część z nich czeka dopiero na publikację. W artykule została wykorzystana wiedza z zakresu socjologii wsi, filozofii rzeczy oraz kabały żydowskiej. Obiektem najintensywniejszego namysłu są podręczne wiejskie narzędzia. Autorka stawia pytanie, z czego wynika ich obecność w wierszach, do czego służą, dlaczego Szewc pamięta o nich w sposób szczególny. Rozważa też, jak na tym tle definiowane są pojęcia elementarne, takie jak wiejskie, 
chłopskie, ludowość czy folklor, co z kolei prowadzi do uwag o charakterze ogólniejszym, czym dzisiaj w poezji jest ludowość i w jaki sposób jej obecna wersja współgra z tradycją. Słowa kluczowe: narzędzia wiejskie, kabała żydowska, ludowość, folklor, wieś, Piotr Szewc

W zakończeniu książki Andrzeja Zawady Gra w ludowe pada znamienne pytanie: „Czym jest ludowość dzisiaj?” wydaje się, mimo upływu lat, wciąż aktualna. Sięgając do przykładów prozy Juliana Kawalca, Wiesława Myśliwskiego i Tadeusza Nowaka, Zawada stwierdza, że ludowość współczesna nie jest kwestią stylu, lecz światopoglądu. Nie należy jej więc szukać na poziomie języka literackiego i jego struktury, ale w antropologicznych warstwach dzieła literackiego, a niekiedy jeszcze niżej, w jego magicznych inkantacjach, marzeniach, niewypowiedzianym. Taka ludowość to pewna wypracowana idea, ale u każdego z pisarzy wypracowana inaczej, poskładana z wielu zmiennych, wywołana najróżniejszymi okolicznościami, z których doświadczenie biograficzne, urodzenia się i wychowania na wsi wydają się najważniejsze.

Od samego początku Zawada unika słowa „ludowe” i zastępuje je określeniem „chłopskie”, uzasadniając swój wybór wieloznacznością i słownikową nieprzeniknionością ludowości ${ }^{2}$. Pozostaje jednak coś więcej niż spór o pryncypia, pozostaje kwestia tożsamości pisarzy włączanych w połowie lat osiemdziesiątych, gdy powstała omawiana książka, do tak zwanego nurtu chłopskiego. Słowo „chłopski” określa w niej znacznie trafniej stawkę „gry w ludowe”, a to wysoka stawka, dotyczy bowiem szukania słów - nowych, choć częściowo osadzonych w przeszłości - dla tego, co znaczy być człowiekiem, jak zdefiniować świat, istnienie, życie. W przypadku wymienionych twórców, przekonuje Zawada, poszukiwanie przynosi pewnego rodzaju ulgę, prowadzi bowiem do apologii chłopskości.

Określenie apologia brzmi w tym kontekście cokolwiek nieściśle, ale - jak sądzę nie fałszywie. Każdy bowiem z tych pisarzy prowadzi spór z chłopskością, przeprowadza jej wiwisekcję, demaskuje jej anachronizmy i subiektywizmy: robi to wszystko jednak po to, by tak rozliczoną, oczyszczoną chłopskość zachować, ocalić literacko, uchronić od przemijania ${ }^{3}$.

W rezultacie, pisze dalej krytyk, powstaje nie skansen chłopskich wartości, lecz literatura rozpięta między bezkompromisowym krytycyzmem a apologią teraźniejszości; to bowiem, co nieutrwalone, nie istnieje, a w wypadku odwołującej się do świata wsi literatury chodzi przecież nie tyle o czyjeś rzeczywiste istnienie,

${ }^{1}$ A. Zawada, Gra w ludowe. Nurt chtopski w prozie wspótczesnej a kultura ludowa, Warszawa 1983, s. 286.

2 Tamże, s. 8.

3 Tamże, s. 289. 
ile o istnienie wyobrażone, które może dać podstawy, górującej nad swoimi korzeniami, nowej antropologii. O taką właśnie nową antropologię chłopskości chciałabym zapytać w tym szkicu, biorąc pod uwagę przede wszystkim konieczność poszukiwania we współczesnym myśleniu o literaturze, odwołującej się do świata wsi i chłopów, pojęć na trwałe w nim zakorzenionych, takich jak literatura ludowa, jej związek z folklorem i „literatura pragnąca”. Analizowana w tym kontekście poezja Piotra Szewca, pisarza urodzonego w Zamościu, ale rodzinnie związanego z Czołkami, wsią w gminie Sitno, pozwala zrozumieć, czym jest nowa chłopska antropologia oraz w jakim sensie pozostaje ona jedynie funkcją prywatnej, poetyckiej pamięci, ale też - jak dalece tę pamięć przekracza i ustanawia literacką socjologię powojennej wsi polskiej.

Poezja Szewca, który swój pierwszy zbiór wierszy Świadectwo wydał w tym samym roku, w którym ukazała się Gra w ludowe Zawady, będzie tu odnoszona do postawionej przez krytyka, a opartej na rozważaniach Rocha Sulimy tezy o dokonującym się w latach siedemdziesiątych (a są to lata wczesnej młodości autora Bocianów nad powiatem) rozpadzie takich pojęć, jak „plebejskość” czy „ludowość”, poprzedzonym obumarciem tkanki społecznej, do której one odsyłają. Jak pisał Zawada o tamtym czasie:

Literatura współczesna (...) skłaniać może do przekonania, że nie istnieje już klasa chłopska w tradycyjnym sensie. W obecnym społeczeństwie, o zatartych granicach klasowych i prawie nieistniejących granicach kulturowych, nie ma już pełnowymiarowej kultury chłopskiej, robotniczej czy inteligenckiej, ludowość nie jest więc i być nie może własnością jednej tylko klasy społecznej. Tymczasem współczesna ludowość jest nie tylko folklorystyczna, jest antyfolklorystyczna nawet ${ }^{5}$.

Moim rozważaniom towarzyszy założenie, że poezję Szewca należy przede wszystkim widzieć w układzie poglądów badaczy starszej generacji, a nie w kontekście najnowszych dyskusji o miejscu polskiej wsi w kulturze ${ }^{6}$. Wpływ na to miały - w zakresie, który będzie mnie tu przede wszystkim interesował, refleksji na temat wsi - wspomnienia poety z okresu dzieciństwa i wczesnej

${ }^{4}$ Określenie pochodzi ze zbioru szkiców Anny Kamieńskiej i odnosi się do twórczości autentystów, pisarzy chłopskich, bardzo emocjonalnie reagujących zarówno na czyjeś słowo pisane, jak i na twórczość własną. „Pragnienie” w tym kontekście jest nieomal synonimem „prawdziwych" emocji, autentyczności.

5 R. Sulima, Folklor i literatura. Szkice o kulturze i literaturze wspótczesnej, wyd. 2 uzup., Warszawa 1985, s. 21.

${ }^{6}$ Por. Chtopska (nie)pamięć. Dziedzictwo chtopskości w polskiej literaturze i kulturze, red. G. Grochowski, D. Krawczyńska, G. Wołowiec, Kraków 2019; P. Biłos, Powieściowe światy Wiestawa Myśliwskiego, Kraków 2017; K. Wawer, Drugi plan. Twórczość Wiestawa Myśliwskiego w perspektywie postkolonialnej, Kraków 2018; J. Majmurek, Potomek chtopów pańszczyźnianych patrzy na Wilanów, „Krytyka Polityczna”, 13.05.2013, nr 29, https://krytykapolityczna.pl/ $\mathrm{kraj} /$ majmurek-potomek-chlopow-panszczyznianych-patrzy-na-wilanow/, dostęp: 19.12.2020. 
młodości, przypadających na lata sześćdziesiąte i siedemdziesiąte. Prawdopodobnie większość poetyckich obrazów wsi w tej poezji została ukształtowana w rezultacie najwcześniejszych doświadczeń dzieciństwa i młodości - do takiego myślenia skłania obecność w niej podmiotu nazywanego często Piotrusiem. Przefiltrowane przez czas doświadczenia, w pewnym sensie będące wspomnieniami poety, w innym - ściśniętymi w określoną formę, oczyszczonymi ideami - nie odgrywają roli komentarza do współczesności, nie poszerzają pola badań nad funkcjonowaniem współczesnej wsi, są prawie wyłącznie domeną prywatnej filozofii Szewca. Czyli tego, co w jednym z wierszy poeta nazywa „całkiem prywatnie”

Napięcia między wiejską rzeczywistością a literaturą autora Zagtady w pewnym sensie przypominają napięcia wytwarzające się między literaturą a folklorem. Są one tylko pozornie spokrewnione, tak naprawdę ustanawiają je bowiem niemal same różnice.

Literatura dopuszcza zmienność światów, kultur, osobowości, gdy folklor raczej przyrównuje i ujednolica, co nie wyklucza jego immanentnych nawet przeobrażeń. Literatura przekracza świat, folklor go reprodukuje, przystosowując się do jego przemian. Na tym polegają między innymi jego ograniczenia (...). Literatura dąży do stworzenia iluzji rzeczywistości wewnętrznie umotywowanej, uporządkowanej zgodnie z wpisanym w nią światopoglądem. Folklor odwrotnie: symbolizuje, upraszcza i konwencjonalizuje rzeczywistość. Literatura stara się dać obraz rzeczywistości, próbuje definiować świat, gdy folklor - będąc obroną przed chaosem świata - tworzy symbole-hasła i znaki orientacji w świecie ${ }^{8}$.

W wypadku twórczości Piotra Szewca różnica między rzeczywistością artystycznie przetworzoną a tym, co można by nazwać światem ludowości bądź wsi, choć raczej nie folklorem ${ }^{9}$, rysuje się mniej ostro. $Z$ jednej strony obserwujemy wieś pozbawioną typowych dla lat siedemdziesiątych napięć, z drugiej widzimy zupełnie innego rodzaju napięcia w samej literaturze. Wszystko to sprawia, że próbując zrozumieć, w jaki sposób Szewc radzi sobie z dziedzictwem wsi oraz doświadczeniami młodości, należy wcześniej odpowiedzieć na pytanie, co oznaczają w jego pisarstwie takie zagadnienia, jak „ludowość”, „wies”" czy wspominany już „folklor”.

Jak pisał Jan Bystroń, „twórczością ludową nazywamy te treści artystyczne, które niezwiązane ustalonym raz tekstem, nierozpowszechniane przez pismo czy druk przechodzą w bezpośredniej tradycji z ust do ust, z pokolenia

7 P. Szewc, Catkiem prywatnie [w:] tegoż, Catkiem prywatnie, Kraków 2006, s. 34.

${ }^{8}$ R. Sulima, dz. cyt., s. 19, 21.

9 Poeta pytany o wpływ folkloru na jego twórczość mówi raczej o braku tego wpływu i wyraźnie rozdziela folklor oraz ludowość od obrazu wsi, jaki konstruuje [z rozmów prywatnych Autorki z Piotrem Szewcem, grudzień 2020 roku]. 
w pokolenie"10. Przy czym doprecyzowania wymaga samo pojęcie ludu, odnoszone dziś do wszystkich podporządkowanych w społeczeństwie polskim, stanowiących jego 90 procent $^{11}$, „ludzi rządzonych, a nie rządzących; biednych, a nie bogatych; zwykle niewykształconych i zawsze podporządkowanych władzy" ${ }^{12}$. W pracach Bystronia ludem są nazywani mieszkańcy wsi, spadkobiercy dawnej kultury Słowian pogańskich, anonimowa gromada tworząca literaturę, a w szczególności poezję ludową. Kierunek takiego myślenia o ludowości, wyznaczony przed wojną pracami Karola Ludwika Konińskiego, Mariana Czuchnowskiego czy Włodzimierza Pietrzaka, potem podjęli między innymi autorzy tygodnika społeczno-literackiego „Wies”, w tym Anna Kamieńska. We wstępie do Piotunowego ziela. Wyboru rosyjskiej liryki ludowej wyjaśniała:

Liryka zaś - przechodząc z ust do ust, będąc pieśnią codzienną ludu - zmieniała się nieustannie, przystosowywana za każdym razem do warunków, do sytuacji (...). Dlatego też pieśń ludowa nie poddaje się tak łatwo pracom badawczym, tak trudno określić jej wiek i okoliczności powstania ${ }^{13}$.

Ani z rozumieniem ludu jako społeczeństwa poddanego dyktatowi władzy państwowej, społeczeństwa uciśnionego, ani z ludem jako społecznością wiejską nie mamy w twórczości Szewca do czynienia. Podobnie jak folklor jest to pojęcie wobec niej zewnętrzne, historyczne, powracające dalekim echem, niemającym w tym wypadku prawie żadnego znaczenia. Wspominam o nim jedynie po to, aby zaznaczyć, jak dalece różna jest to poezja od powojennej liryki łączonej z tak zwanym pisarstwem samorodnym, o którym Kamieńska pisała - powołując się na przykład Stanisława Piętaka czy, skądinąd lubianego przez Szewca, Jana Bolesława Ożoga - że ten typ ludowości właściwie już nie istnieje ${ }^{14}$. Jej echa, słyszalne w poezji Szewca, potomka chłopów spod Zamościa, to nic innego jak literackie przetworzenie, „uczynienie [jejdop. M.T.] wartościami ogólnoludzkimi i w pełnym tego słowa znaczeniu artystycznymi" 15 .

Począwszy od lat dwutysięcznych w poezji Szewca pojawiają się wiersze poświęcone Czołkom, miejscu, gdzie poeta spędził pierwsze lata życia,

10 J.S. Bystroń, Literatura ludowa [w:] tegoż, Tematy, które mi odradzano. Pisma etnograficzne rozproszone, wybór i oprac. L. Stomma, Warszawa 1980, s. 357.

11 A. Leszczyński, Ludowa historia Polski. Historia wyzysku i oporu. Mitologia panowania, Warszawa 2020, s. 569.

12 Tamże.

13 A. Kamieńska, Przedmowa [do:] Piotunowe ziele. Wybór rosyjskiej liryki ludowej, tłum. A. Kamieńska, Warszawa 1961, s. 6.

${ }^{14}$ Taż, Pragnaca literatura. Problemy pisarstwa ludowego i nurtu ludowego poezji wspótczesnej, Warszawa 1964, s. 9.

15 Tamże. 
„emocjonalnie najważniejsze” ${ }^{16}$. Ich bohaterami są najczęściej Alfreda i Edward Twardziszewscy, rodzice matki poety Wandy Szewc. Oboje żyli z uprawy ziemi i hodowli zwierząt. Dziadek poety rozpoczął przed wojną naukę w gimnazjum (której nie skończył), po wojnie prowadził czołecki oddział kółka rolniczego, zajmował się także kilkoma hektarami własnej ziemi. Alfreda Twardziszewska towarzyszyła mu w pracy, była też ukochaną babcią poety. Zmarła siedemnaście lat po śmierci męża, w 2008 roku. Poezja Szewca opowiada ich historię fragmentarycznie. Częściej pojawiają się pojedyncze obrazy emocjonalnego związku Piotrusia z babcią niż fakty z życia czołeckiej społeczności; nie one interesują poetę, co nie oznacza jednak, że o tych faktach zapomina. Przeciwnie, fakty zamienia na imiona i nazwiska, jest wyjątkowym kronikarzem pojedynczych, ludzkich losów. Dzięki poezji Szewca społeczność Czołek drugiej połowy XX wieku - rzec można nieco na wyrost - zyskała naprawdę długie życie pośmiertne. Uczuciowe związki poety z krajobrazem dzieciństwa i młodości mniej są tu istotne. Uważam bowiem, że szczególne residuum chłopskiej wrażliwości poety, tak czy inaczej budowanej, zmienianej, a nawet krytykowanej przez niego samego, tworzą narzędzia rolnicze, budynki w gospodarstwie rolnym, a także drobne utensylia, bezpośrednio związane z chowem zwierząt czy uprawą roślin. Jak żaden inny współczesny poeta Szewc stosuje te narzędzia, opisuje budynki, używa drobnych przedmiotów z wyjątkową dbałością o szczegót. Trudno ją jednak ograniczać do, znanej z Zagtady czy Zmierzchów i poranków, precyzji języka, staranności w odtwarzaniu realiów przedwojennego Zamościa czy pietyzmu w opisywaniu rzeczy. Fajtak, sagan i worki konopne pełnią tu zupełnie inną funkcję, mają charakter pewnego intelektualnego zaskoczenia, mogą budzić zdziwienie - po pierwsze bowiem, nie są to przedmioty o jasnym dla czytelnika znaczeniu, po drugie, o czym Szewc doskonale wie, wiele z nich utraciło swoje desygnaty bądź w takiej postaci, w jakiej opisuje je poeta, już nie funkcjonują. Ich obecność w poezji współczesnej przykuwa jednak uwagę podobnie jak aeroplan w wierszu Stanisława Młodożeńca opublikowanym w $1921 \mathrm{roku}^{17}$. To, co u futurysty było znakiem bulwersującej nowością, poetyckiej technologii, u Szewca przemienia się w anachronizm o zastanawiającej sile.

Znamienne pod tym względem wydają się dwa wiersze: Związ to z 2008 roku i Ksztatt chwili z 2012 roku. Oba dotyczą pracy w polu, żniw i sianokosów, zbiorów pszenicy, pracy takich maszyn, jak traktor czy snopowiązałka, przygotowywania sznurków konopnych, powróseł; gdzieś w tle rysuje się sytuacja liryczna, dotycząca wakacji spędzanych przez dziecięcego bohatera obu tych poetyckich opowieści w Czołkach i jego udziału w pracach polowych (przypatruje

16 Szukam miary dla swoich spraw. Z Piotrem Szewcem rozmawia Marta Tomczok, „Nowe Książki” 2019, nr 12, s. 8.

${ }_{17}$ S. Młodożeniec, XX wiek [w:] Antologia polskiego futuryzmu i Nowej Sztuki, wybór i przygot. tekstów H. Zaworska, Wrocław-Warszawa-Kraków-Gdańsk 1978, s. 181. 
się, pomaga, podaje, obserwuje). Jednak tym, co wyróżnia wspomniane utwory spośród innych tekstów Szewca, związanych ze wsią i rolnictwem, jest czas teraźniejszy, nadający opisywanym zdarzeniom cechy trwałości, nieustannego dziania się, jakby stale powracającego, ponawianego rytuału. Dziadek zdaje się klepać kosę nieprzerwanie, a w snopowiązałce od lat nie gaśnie silnik. Ów nieprzerwany ruch, wieczne zbieranie plonu nie są jednak oczywistymi znakami mitu, wykreowanymi na podstawie czytelnego wzorca. Wspomniane elementy wiejskiej kultury materialnej, które koncentrują na sobie uwagę czytelnika, sprowadzają tę pracę przede wszystkim do detali:

Od Stabrowa po Łapiguz powietrze faluje korona

dzikiej gruszy buja się wokół ostów owady w transie słońce znieruchomiało za stodołą między jabłoniami podniosły się krowy zmęczony ciągnik charczy staje rusza snopowiązałka kosi pszenicę nawraca nie czuję jak konopny sznurek rani dłonie koniki polne skaczą na rozrzucone kłosy rżysko drogi żółty pył opada babcia wyciera czoło Piotrusiu mówi zrób powrósło zwiąż to ${ }^{18}$.

Czy można inaczej przeczytać słowa babci skierowane do wnuka niż jako prośbę o pomoc? Określenia takie jak „zmęczony ciągnik”, „stodoła”, „snopowiązałka”, „konopny sznurek”, „rżysko” czy właśnie „powrósło” wydają się przesłaniać tę prośbę i tworzyć dość niepozorną, skomplikowaną sieć nieokreślonych znaczeń. Ich niekończąca się praca nie jest pracą ludzkich rąk, nie powoduje zmęczenia, nie można jej więc odnosić do ucisku panującego na polskiej wsi od setek lat. Maszyny zdają się na polu same, pozostają wyalienowane, ludzi tu bowiem prawie w ogóle nie ma. Zmęczenie rolników sprowadza się właściwie do stwierdzenia: „babcia/ wyciera czoło Piotrusiu mówi zrób powrósło zwiąż to". Wyalienowana praca maszyn nie ma więc wymiaru antropologicznego, jest środkiem mitu o nieznanym znaczeniu. W podobny sposób został ukształtowany drugi z wierszy:

Początek wakacji dziadek klepie kosę Czołki dźwięczą miarowo dochodzi południe po krzakach kury sennie gdaczą zadzieram głowę wysoko daleko białe zielone błękitne jak stado szpaków (...) czas kołuje podobno wraca to co minęło ${ }^{19}$.

Tutaj także rozpędzony letnim słońcem świat pozostaje w nieustającym ruchu; wprawdzie ów ruch wydaje się leniwy, wręcz senny, wiatr delikatnie porusza zbożem, nic jednak nie zapowiada, by miał nastąpić jakiś koniec, by miała

18 P. Szewc, Zwią̇̇ to [w:] tegoż, Tymczasem. Wybór wierszy, Poznań 2019, s. 38.

19 Tenże, Kształt chwilowy [w:] tegoż, Tymczasem..., dz. cyt., s. 53. 
zajść zmiana. Szewc wpisuje tę rzeczywistość raczej w mit wiecznego powrotu, nadaje jej wymiar kolisty, uwydatnia się on jednak często właśnie za sprawą nieprzerwanie pracujących (jakby samoistnych) narzędzi i maszyn, jak w niepublikowanym wierszu Cztery ursusy, gdzie po traktorach pamiętających czasy „wczesnego Gierka” pozostały nie tylko ślady kół odciśnięte w ziemi, ale wręcz cały czas słychać „,warkot silników hałas zaczepianego pługa/ stukanie młotka głośne zamykanie burt przyczepy" ${ }^{20}$. Rolą tych odosobnionych przedmiotów, istniejących mimo upływu czasu w jakimś magicznym wymiarze, jest bardzo często umożliwienie podmiotowi dokonania reorientacji, przedostania się do przeszłości tam, gdzie normalnie nie miałby wstępu. W takiej roli występuje na przykład sagan, w którym jeden z sąsiadów gotował dla świń i kur ziemniaki:

Wysoki i pękaty, stał na rozgrzanych fajerkach węglowego pieca. Mocny, jak przystało na naczynie z żeliwa. Pan Kawa parował w nim ziemniaki dla kur i świń. Zaglądałem do niego, wąchałem pachnące ugotowanymi łupinami wnętrze. Ja rosłem, a on wciąż był taki sam. I jest nadal, choć nie ma pana Kawy ani tamtego pieca. Trzymam się ucha sagana, a może to ucho mnie trzyma, bym zachował jego kształt i chropawą pod palcami dziecka skórę ${ }^{21}$.

Niezwykła trwałość przedmiotów, stających się po pewnym czasie czymś więcej niż potencjalnym eksponatem muzealniczym, ujawniona zostaje przez Szewca nie tylko w odniesieniu do maszyn i narzędzi służących do pracy w gospodarstwie bądź na polu. Podobne znaczenie ma na przykład młynek do kawy podarowany rodzinie przez bohatera wiersza z 2016 roku:

Czy mógłbym przypuszczać że elektryczny młynek do kawy który kupiłem w latach studenckich przeżyje dziadka ojca a nawet babcię i mamę wciąż pachnie Czołkami $(\ldots)^{22}$.

Obok narzędzi trwałych, wirujących nieustannie w bezczasie tej poezji, istnieje znacznie liczniejsza grupa przedmiotów uszkodzonych, zniszczonych i rozsypujących się na kawałki. Należą do nich przede wszystkim obiekty niebędące narzędziami, takie jak stodoły. W wierszu Tylko tymczasem, od którego wziął tytuł wybór poezji Szewca z 2019 roku, czytamy:

Stodoła rozleciała się wiatr czesze zeszłoroczną trawę na klepisku koło ciągnika odcisnęło ślad ale i on tylko tymczasem gdzieżbyś nie pamiętała ciepło ubrani bo

20 Tenże, Cztery ursusy [wiersz niepublikowany z 2020, cytuję dzięki uprzejmości Poety].

${ }^{21}$ Tenże, Sagan pana Kawy [w:] tegoż, Po nitce, Kraków [tom przygotowany do druku, s. 24].

${ }^{22}$ Tenże, Mtynek do kawy [w:] tegoż, Światetko, Kraków 2017, s. 49. 
listopad lub grudzień nad wanną nożem otwieraliśmy makówki strasznie mnie to nudziło...23

Utworem o rozpadzie domu, zanieczyszczonych piecach i przeciekającym dachu zaczyna się tom Catkiem prywatnie ${ }^{24}$, z kolei zbiór Światetko otwiera obraz zardzewiałej furtki prowadzącej do dawnego dziecięcego raju - domu dziadków Twardziszewskich ${ }^{25}$. Jednak dopiero obrazy nieczynnych maszyn bądź uszkodzonych narzędzi sygnalizują proces rozpadu wewnętrznego świata podmiotu; to bowiem, co miało go stwarzać, wprawiać w ruch, ożywiać, nagle psuje się i osuwa w nicość jak w wierszu Rachuby, gdzie cały, z trudem wzniesiony świat wiejskich roślin i zwierząt, oczekujący na tytułowe rachunki i pomiary, dokonane ręką dziadka, posługującego się fajtakiem, nagle niknie w przepaści:

Gdy dziadek fajtakiem wiosną mierzył zagony przypominał

Astronoma z wielkim cyrklem ziemia kurczyła się i rozszerzała

Wznosiła kilka kroków dalej niż przed rokiem niosły ją racice

Kopyta koła raniły motyki kroiły pługi ziemniaki nie wiedziały

Że przed nimi była tu koniczyna (...)

Ale rzeczy wymagały sprawdzenia

Przepaść otwierała usta po zmierzchu

Wpadały w nią furmanki krowy niepewni dnia sąsiedzi ${ }^{26}$.

Szewc nie formułuje tu żadnej socjologicznej diagnozy, nie jest to wiersz-alegoria. Sformułowanie czegoś takiego byłoby zresztą niemożliwe, ponieważ - jak pisze Izabella Bukraba-Rylska - „to nie wieś i rolnictwo są niedostosowane do makroukładu, lecz raczej otaczający je system społeczno-gospodarczy jest niedostosowany do ich potrzeb”27. Wytwarzające się w ten sposób napięcia między społecznością wiejską a jej otoczeniem, w tym także między znaczeniem wierszy o wsi a ich odbiorcami, szczegółowo oddają wymienione nazwy narzędzi i maszyn. Część z nich należy jeszcze do rzeczywistości sprzed 1918 roku. Autorzy wielotomowej Historii kultury materialnej, pisząc o wsi z początku XX wieku, wymieniają między innymi pługi, brony, snopowiązałki, przetaki czy sieczkar$n^{2} e^{28}$. Niektóre z maszyn rolniczych starszego typu pojawiają się także u Szewca, jednak ich ciągle uruchamianie, praca, ale i psucie się, a wreszcie niszczenie wprawiają świat tej poezji w jeszcze inny ruch niż opisany w Rachubach, kurczenia i rozszerzania się. Odpowiadają one - choć to jedynie analogia - zasadzie

23 Tenże, Tylko tymczasem [w:] tegoż, Cienka szyba, Kraków 2014, s. 18.

${ }^{24}$ Tenże, Stare piece [w:] tegoż, Catkiem prywatnie, dz. cyt., s. 6.

25 Tenże, Popycham furtkę [w:] tegoż, Światetko, dz. cyt., s. 5.

26 Tenże, Rachuby [w:] tegoż, Tymczasem..., dz. cyt., s. 86.

27 I. Bukraba-Rylska, Socjologia wsi polskiej, Warszawa 2008, s. 301.

${ }^{28}$ Historia kultury materialnej Polski w zarysie, oprac. zbiorowe, red. W. Hensel, J. Pazdur, t. 6: Od 1870 do 1918 roku, red. B. Baranowski, J. Bartyś, T. Sobczak, Wrocław 1979, s. 72-93. 
cimcum, według koncepcji Isaaka Lurii oznaczającej wycofywanie sił Boskich ze świata, koncentrację, przeniesienie w inne miejsce. Towarzyszą temu najczęściej dwa inne działania: przypływu i odpływu kurczenia się i rozszerzania (nazywane odpowiednio hitpaszut, siłą odśrodkową, oraz histalkut, siłą dośrodkową) ${ }^{29}$. Zdaniem Gershoma Scholema:

[p]odobnie jak organizm ludzki trwa dzięki podwójnemu procesowi wdychania i wydychania, wzajem od siebie nieoddzielnych, tak też całość stworzenia to tylko wdech i wydech boskiego życia. W głębszym sensie korzeń wszelkiego zła tkwi zatem w świecie, potencjalnie ukryty jest już w samym akcie cimcum, mianowicie w kategorii mocy sądu $(D i n)^{30}$.

O rozpadzie świata, którego nie chroni już żadna Boska siła, mówią dwa nowe wiersze: Przed budzikiem z 2018 roku i Worki konopne z 2020 roku. W obu wypadkach rzeczy używane w gospodarstwie, jak sito do noszenia gołębiom pszenicy czy worki mieszczące „ziemniaki marchew otręby zboże”31, zostają podziurawione przez myszy, przestają być więc symbolami schronienia (choć wcześniej „dawały schronienie/ i naszemu światu”), a ich rozpad, namacalny, dosłowny, nie do odwrócenia (jak naprawić sito? W jaki sposób zszyć stare worki?), przypomina w pewnym sensie opisywane w kabale luriańskiej rozbicie naczyń. W myśl tej koncepcji ponowna naprawa świata (tikkun) ma się dokonać za sprawą światła sefirot układającego się w nowe konfiguracje; w procesie tikkun Bóg sam siebie kształtuje „w doskonałą, pełną osobę" ${ }^{2}$. W poezji Szewca stare, zużyte narzędzia i maszyny rolnicze nie zostają naprawione, tracą moc pośredniczenia w minionym, nie kierują w stronę przeszłości. Jednak rozedrganie tego świata, rozpostartego między procesy kurczenia się i rozkurczania, rozpadu i trwałości, wydaje się wciąż na nowo go uruchamiać. Trzeba jednak pamiętać o czymś w tej sytuacji naturalnym: o postępującym procesie niszczenia, o coraz bardziej dławiącej sile niepamięci. W kabale definitywnym końcem zniszczenia jest nadejście Mesjasza, w chrześcijaństwie odnowienie nadejdzie wraz z paruzją, ponownym zstąpieniem Chrystusa na ziemię. Kosmogonia Szewca, w której ważną rolę odgrywa nie tyle immanencja, ile jej odpryski, proste przedmioty niegdyś związane z pracą chłopów pozbawione mitologii, opiera się na rytuałach mistycznych swobodnie i wybiórczo. Utrzymuje ona obraz wsi polskiej lat sześćdziesiątych, siedemdziesiątych i późniejszych w stanie pewnego „zamrożenia”, jednak stosunek do tamtego świata i jego trwałości poeta ma dość ambiwalentny:

${ }^{29}$ G. Scholem, Mistycyzm żydowski i jego gtówne kierunki, tłum. I. Kania, wstęp M. Galas, Warszawa 1997, s. 325.

30 Tamże.

31 P. Szewc, Worki konopne, „Akcent” 2020, nr 2, s. 7-8.

32 G. Scholem, dz. cyt., s. 331. 
Mam ogromny szacunek do zamojsko-czołeckiego świata. Ten świat uległ rozpadowi, dekonstrukcji nie tylko materialnej, ale i społecznej, obyczajowej, kulturowej. Za dekonstrukcją poszło przeobrażenie, bo jedno ustąpiło, by dać miejsce innemu, ale już z tym „innym” nie mam więzów emocjonalnych. Jesteśmy sobie prawie obcy, obojętni (...). Jako kilkunastoletniemu chłopakowi nie przyszłoby mi do głowy, że moja ziemia rodzinna, jej mieszkańcy, budowle, przyroda wywrą na mnie przemożny wpływ. Teraz z owego wpływu korzystam, ile mogę. Pełnia była wtedy i tam. Tam się mieści mój cały świat, mnie on wystarcza i w nim czuję się u siebie ${ }^{33}$.

W zakończeniu Gdy w ludowe Zawada pisał: „Literacki proces emancypacji klasy chłopskiej jest już zakończony. Literatura mająca w rodowodzie te doświadczenia, może teraz pytać o naszą tożsamość” ${ }^{34}$. W pamięci poezji Piotra Szewca istnieją wszystkie elementarne dla twórczości opartej na doświadczeniu chłopskim kategorie, kształtują one jednak już nie odrębną wobec tej twórczości socjologię, ale prywatną antropologię pisarza, w której ważną funkcję pełni konkret. Zadaniem krytyki pozostaje zrozumieć jego historyczność, odnaleźć desygnaty, a także pytać o rolę, jaką odgrywa on współcześnie. Przekracza ona z pewnością granice zjawiska nazywanego przez Zawadę „grą w ludowe”, nie jest też częścią przewrotnej zabawy; wyobraźnia poetycka Szewca pewnie już zawsze będzie się żywić wiejskim konkretem, ale będzie on też pod wpływem czasu coraz bardziej oczyszczony z ziemi, coraz bardziej krystaliczny i trudniejszy do zrozumienia bądź oceny. Istnieje prawdopodobieństwo, że narzędzia powrotu - jak je tu nazwałam - staną się kiedyś pojedynczymi, wyizolowanymi z rzeczywistości, która je stworzyła, bytami. Kolejne tomiki wierszy pokażą, jak będzie przebiegał proces tego oczyszczania.

\section{Bibliografia}

Biłos P., Powieściowe światy Wiestawa Myśliwskiego, Kraków 2017.

Bukraba-Rylska I., Socjologia wsi polskiej, Warszawa 2008.

Bystroń J., Literatura ludowa [w:] tegoż, Tematy, które mi odradzano. Pisma etnograficzne rozproszone, wybór i oprac. L. Stomma, Warszawa 1980.

Chtopska (nie)pamięć. Dziedzictwo chtopskości w polskiej literaturze i kulturze, red. G. Grochowski, D. Krawczyńska, G. Wołowiec, Kraków 2019.

Historia kultury materialnej Polski w zarysie, oprac. zbiorowe, red. W. Hensel, J. Pazdur, t. 6: Od 1870 do 1918 roku, red. B. Baranowski, J. Bartyś, T. Sobczak, Wrocław 1979.

33 Szukam miary dla swoich spraw..., dz. cyt., s. 7-8.

${ }^{34}$ A. Zawada, dz. cyt., s. 297. 
Kamieńska A., Pragnaca literatura. Problemy pisarstwa ludowego i nurtu ludowego poezji wspótczesnej, Warszawa 1964.

Kamieńska A., Przedmowa [do:] Piotunowe ziele. Wybór rosyjskiej liryki ludowej, tłum. A. Kamieńska, Warszawa 1961.

Leszczyński A., Ludowa historia Polski. Historia wyzysku i oporu. Mitologia panowania, Warszawa 2020.

Majmurek J., Potomek chtopów pańszczyźnianych patrzy na Wilanów, „Krytyka Polityczna”, 13.05.2013, nr 29, https://krytykapolityczna.pl/kraj/majmurek-potomek-chlopow-panszczyznianych-patrzy-na-wilanow/, dostęp: 19.12.2020.

Młodożeniec S., XX wiek [w:] Antologia polskiego futuryzmu i Nowej Sztuki, wybór i przygot. tekstów H. Zaworska, Wrocław-Warszawa-Kraków-Gdańsk 1978.

Scholem G., Mistycyzm żydowski i jego gtówne kierunki, tłum. I. Kania, wstęp M. Galas, Warszawa 1997.

Sulima R., Folklor i literatura. Szkice o kulturze i literaturze wspótczesnej, wyd. 2 uzup., Warszawa 1985.

Szewc P., Catkiem prywatnie, Kraków 2006.

Szewc P., Cienka szyba, Kraków 2014.

Szewc P., Cztery ursusy [wiersz niepublikowany z 2020].

Szewc P., Po nitce, Kraków [tom przygotowany do druku].

Szewc P., Światetko, Kraków 2017.

Szewc P., Tymczasem. Wybór wierszy, Poznań 2019.

Szewc P., Worki konopne, „Akcent” 2020, nr 2.

Szukam miary dla swoich spraw. Z Piotrem Szewcem rozmawia Marta Tomczok, „Nowe Książki” 2019, nr 12.

Wawer K., Drugi plan. Twórczość Wiestawa Myśliwskiego w perspektywie postkolonialnej, Kraków 2018.

Zawada A., Gra w ludowe. Nurt chtopski w prozie wspótczesnej a kultura ludowa, Warszawa 1983. 